\title{
A Clinician's Guide to the Diagnosis and Treatment of Candidiasis in Patients with Psoriasis
}

\author{
April W. Armstrong ${ }^{1} \cdot$ Michael Bukhalo ${ }^{2} \cdot$ Andrew Blauvelt $^{3}$
}

Published online: 19 July 2016

(c) The Author(s) 2016. This article is published with open access at Springerlink.com

\begin{abstract}
Many of the molecular pathways associated with psoriasis pathogenesis are also involved in host defense mechanisms that protect against common pathogens. Candida can stimulate the production of cytokines that trigger or exacerbate psoriasis, and many systemic psoriasis treatments may put patients at increased risk for developing oral, cutaneous, and genitourinary candidiasis. Therefore, dermatologists should regularly screen patients with psoriasis for signs of Candida infection, and take steps to effectively treat these infections to prevent worsening of psoriasis symptoms. This review provides an overview of candidiasis epidemiology in patients with psoriasis, followed by a primer on the diagnosis and treatment of superficial Candida infections, with specific guidance for patients with psoriasis. Candidiasis in patients with psoriasis typically responds to topical or oral antifungal therapy. While biologic agents used to treat moderate-to-severe psoriasis, such as tumor necrosis factor- $\alpha$ inhibitors and interleukin-17 inhibitors, are known to increase patients' risk of developing localized candidiasis, the overall risk of
\end{abstract}

Enhanced content To view enhanced content for this article, please go to http://www.medengine.com/Redeem/0AD4F0604E37A968.

Electronic supplementary material The online version of this article (doi:10.1007/s40257-016-0206-4) contains supplementary material, which is available to authorized users.

April W. Armstrong

aprilarmstrong@post.harvard.edu

1 Keck School of Medicine, University of Southern California, 1975 Zonal Avenue, Keith Administration Building, Room 510, Los Angeles, CA 90089, USA

2 Altman Dermatology Associates, Arlington Heights, IL, USA

3 Oregon Medical Research Center, Portland, OR, USA infection is low, and candidiasis can be effectively managed in most patients while receiving systemic psoriasis therapies. Thus, the development of candidiasis does not usually necessitate changes to psoriasis treatment regimens.

\section{Key Points}

Patients receiving systemic therapy for psoriasis may be at an increased risk of developing Candida infections.

This article provides clinical guidance on diagnosing and treating candidiasis in patients with psoriasis.

We posit that, in most cases, candidiasis can be effectively and safely treated without discontinuation of systemic psoriasis therapy.

\section{Introduction}

Psoriasis is a systemic inflammatory disease in which dysregulation of the immune system results in overexpression of inflammatory cytokines [1]. Several of these cytokines (e.g. interleukin [IL]-22, IL-23, and IL-17) are also involved in host defense mechanisms against common pathogens, including Candida species (spp.) [2-5]. Some Candida spp. secrete toxins that exacerbate psoriasis, and it has been hypothesized that the presence of $C$. albicans in the gut can stimulate production of superantigens, causing non-specific T-cell activation and production of cytokines 
that can trigger the psoriatic process [6-8]. Thus, candidiasis is a recognized trigger for psoriasis exacerbations and persistence, and patients with psoriasis may be at risk for subclinical Candida colonization and infections of the skin, mouth, and intestinal tract [6-9].

Several psoriasis treatments may further increase patients' risk for developing fungal infections [10]. For example, oral candidiasis has been noted in patients using topical corticosteroids for psoriasis [11], and systemic immunosuppressive agents used to treat psoriasis (e.g. methotrexate and cyclosporine) are associated with increased rates of oral and disseminated candidiasis [12-14]. Additionally, increased Candida colonization and mild or moderate localized Candida infections have been reported in patients receiving biologic therapy for psoriasis and other inflammatory diseases (e.g. Crohn's disease) [14-18].

Dermatology practitioners who treat patients with psoriasis need to be aware of the signs and symptoms of candidiasis, as well as the recommended candidiasis treatment guidelines. This article presents an overview of candidiasis epidemiology in patients with psoriasis, followed by a primer for dermatologists on the diagnosis and treatment of superficial oropharyngeal, cutaneous, and genitourinary candidiasis.

\section{Candidiasis Overview}

There are more than 200 known species of Candida [7], a ubiquitous eukaryotic yeast that is part of the normal microbial flora of the skin, gastrointestinal tract, and genitourinary tract in healthy individuals $[19,20]$. When host immunity is compromised, the risk of developing opportunistic Candida infections increases [19]. C. albicans is the most common species associated with Candida infections [19], which often presents as oral thrush, vulvovaginitis, or cutaneous candidiasis [7]. Predisposing factors for candidiasis include diabetes and other endocrinopathies, obesity, pregnancy, underlying HIV infection, poor hygiene, and recent treatment with antibiotics or corticosteroids [19, 21, 22]. Individuals who wear dentures are also at increased risk for oral candidiasis [21].

\section{Candidiasis Epidemiology in Patients with Psoriasis}

The fungal microbiome is more diverse and has a different distribution of species in the skin of patients with psoriasis compared with healthy individuals [23]. Oral, cutaneous, and fecal Candida colonization is significantly more common in patients with psoriasis than in individuals without psoriasis $[6,7,24]$. A recent study by Picciani and colleagues [24] found that $26 \%(37 / 140)$ of patients with psoriasis tested positive for oral candidiasis compared with 0 of 140 healthy controls. In this study, candidiasis was more common in patients with severe psoriasis (Psoriasis Area and Severity Index score $>12$ ) than in those with mild or moderate disease [24]; however, other studies have found no association between candidiasis and psoriasis severity $[6,7]$.

In another recent study by Sarvtin and colleagues [7], Candida spp. were isolated in $15 \%$ of skin specimens from patients with psoriasis compared with $4 \%$ of controls $(p=0.045)$, and in oral specimens of $60 \%$ of patients with psoriasis compared with $20 \%$ of controls $(p<0.01)$. Serum immunoglobulin (Ig) M, IgA, and IgG antibody levels against $C$. albicans were lower in patients with psoriasis compared with controls, suggesting that psoriasis may be associated with a reduction in humoral immune responses [7].

Candida colonization is not rare in intertriginous regions of patients with psoriasis [9]. Practitioners should also be aware that symptoms of intertriginous psoriasis can be similar to those of vulvovaginal candidiasis (VVC), and both of these conditions should be considered in the differential diagnosis of patients with vulval pruritus, inflammation, and erythema. Notably, it is prudent to consider intertriginous psoriasis in prepubescent girls because chronic VVC is uncommon in this population [25]. In a chart review of prepubertal girls with chronic vulvitis, Fischer [25] observed that $71 \%$ (27/38) had signs of psoriasis on skin examination, and no patients had evidence of VVC.

Nail onycholysis is a common finding in patients with Candida infections, and also in patients with plaque or pustular psoriasis [26]. Patients who develop psoriatic nail deformities (e.g. pitting, oil spots, or thickening/crumbling of the nail plate) are at increased risk for developing comorbid opportunistic onychomycosis because the compromised nail bed creates an environment where fungi can thrive [26, 27]. Zisova and colleagues [27] found that $62 \%$ (141/228) of patients with psoriasis-related nail changes tested positive for fungal agents and, in $24 \%$ (34/141) of these cases, Candida spp. were identified as causative agents (predominantly $C$. albicans). Patients with the highest Nail Psoriasis Severity Index scores were most likely to test positive for Candida colonization [27]. However, anticandidal treatment has not been shown to eliminate fingernail onycholysis, and the frequent isolation of Candida from onycholytic nails in patients with psoriasis may be due to the close functional proximity of the fingers to the vaginal and gastrointestinal tract, which commonly harbor $C$. albicans [26]. In these patients, nail onycholysis may be most effectively improved by treating 
the underlying nail psoriasis. Typically, specific treatment for onycholytic nails is not necessary unless the patient experiences functional disability.

\section{Diagnosis and Treatment of Candidiasis in Patients with Psoriasis}

\subsection{Oral Candidiasis}

Oropharyngeal candidiasis has been classified into four clinical variants [28]. Acute pseudomembranous candidiasis (thrush) is the most common form and is characterized by white, curd-like lesions that can be dislodged with gentle scraping, revealing underlying erosions (Fig. 1a) [28]. Erythematous candidiasis (also referred to as chronic atrophic candidiasis or denture stomatitis) is characterized by red, atrophic plaques on the tongue and oral mucosa that are often found at the point of mucosal contact with dentures [21, 28]. Chronic hyperplastic candidiasis resembles leukoplakia and presents as thickened white plaques on the gums and inside the cheeks that cannot be easily scraped off [28]. Angular cheilitis, or perleche, is characterized by erythema or fissuring at the corners of the mouth and is common in patients with dentures [28]. In rare cases, oral infections may spread to the pharynx or esophagus [28].

Patients with oral candidiasis can be asymptomatic or may report pain, burning sensations, sore throat, difficulty swallowing, and/or halitosis [21, 28]. While oral candidiasis can usually be diagnosed through physical examination and clinical history [24, 28], the European Society of Clinical Microbiology and Infectious Diseases guidelines for the diagnosis of Candida diseases recommend culturing a swab of a lesion on selective media [29]. Traditionally, microscopic examination using potassium hydroxide $(\mathrm{KOH})$ or fungal cultures are both effective and sensitive methods for detection of oral Candida colonization.

Guideline recommendations from the Infectious Diseases Society of America (IDSA) for the treatment of oropharyngeal candidiasis are summarized in Table 1. Topical therapy (e.g. clotrimazole troches or nystatin suspensions or pastilles) is recommended as first-line treatment for patients with an initial episode of mild disease (strength of recommendation: B) [30]. The recommended initial treatment for moderate-to-severe disease is oral fluconazole $100-200 \mathrm{mg}(3 \mathrm{mg} / \mathrm{kg})$ once-daily for 7-14 days (strength of recommendation: A) [30]. For esophageal candidiasis, systemic antifungal therapy is always required, and oral fluconazole $200-400 \mathrm{mg}(3-6 \mathrm{mg} / \mathrm{kg})$ daily for 14-21 days is recommended (strength of recommendation: A) [30].

\subsection{Cutaneous Candidiasis}

Cutaneous candidiasis usually affects intertriginous areas, such as the groin, abdominal skin folds, and inframammary skin, but can also occur in interdigital spaces [21]. Typically, cutaneous candidiasis presents as thin, bright-red plaques that can be erosive, dry, scaly, oozing, or macerated (Fig. 1b); pustules and collarette scales may also be present [21]. Diagnosis of cutaneous candidiasis is usually based on clinical appearance of the skin, the presence of pseudohyphae in $\mathrm{KOH}$ wet mounts, or positive fungal culture of scrapings from affected areas.

IDSA guidelines recommend topical triazoles and polyenes (e.g. clotrimazole, miconazole, and nystatin) for the treatment of cutaneous candidiasis [31]. Affected areas should be kept dry and, if necessary, Burrow's solution compresses can be used as a drying agent [22, 31].

\subsection{Vulvovaginal Candidiasis}

It is estimated that $75 \%$ of all women experience at least one VVC infection during their childbearing years [32]. Symptoms of VVC can include vulvar pruritus and burning, and soreness and irritation can lead to dyspareunia and dysuria [32]. Concurrent fungal infections can worsen psoriasis; therefore, it is important for VVC to be identified and treated quickly in this population [33].

VVC is often diagnosed based on clinical history and physical examination showing signs of vulvar and vaginal erythema, edema, excoriation, fissures, and/or thick, curdlike vaginal discharge (Fig. 1c) [30, 32]. IDSA guidelines recommend confirming diagnosis with a wet-mount preparation in saline and $10 \% \mathrm{KOH}$, and a check of vaginal $\mathrm{pH}$, which should be normal $(<4.5)$, before beginning antifungal treatment [30]. Cultures should be obtained for patients with negative wet-mount findings [30].

Most (approximately $90 \%$ ) cases of VVC are uncomplicated, and IDSA guidelines recommend treatment with topical antifungal agents (Table 2) or a single $150 \mathrm{mg}$ dose of oral fluconazole (strength of recommendation: A) [30]. A number of topical antifungal agents are effective treatments for uncomplicated VVC, with no agent showing clear superiority. Response rates are generally high (>90\%) and comparable with topical versus oral therapies, whether given as a short course or as single-dose therapy [30]. Because there are many available therapies that are safe and effective for uncomplicated VVC, patient preference (e.g. for oral vs. topical therapy) should be considered when making treatment decisions [34].

Complicated VVC is defined as severe or recurrent disease, infection due to a Candida species other than $C$. 

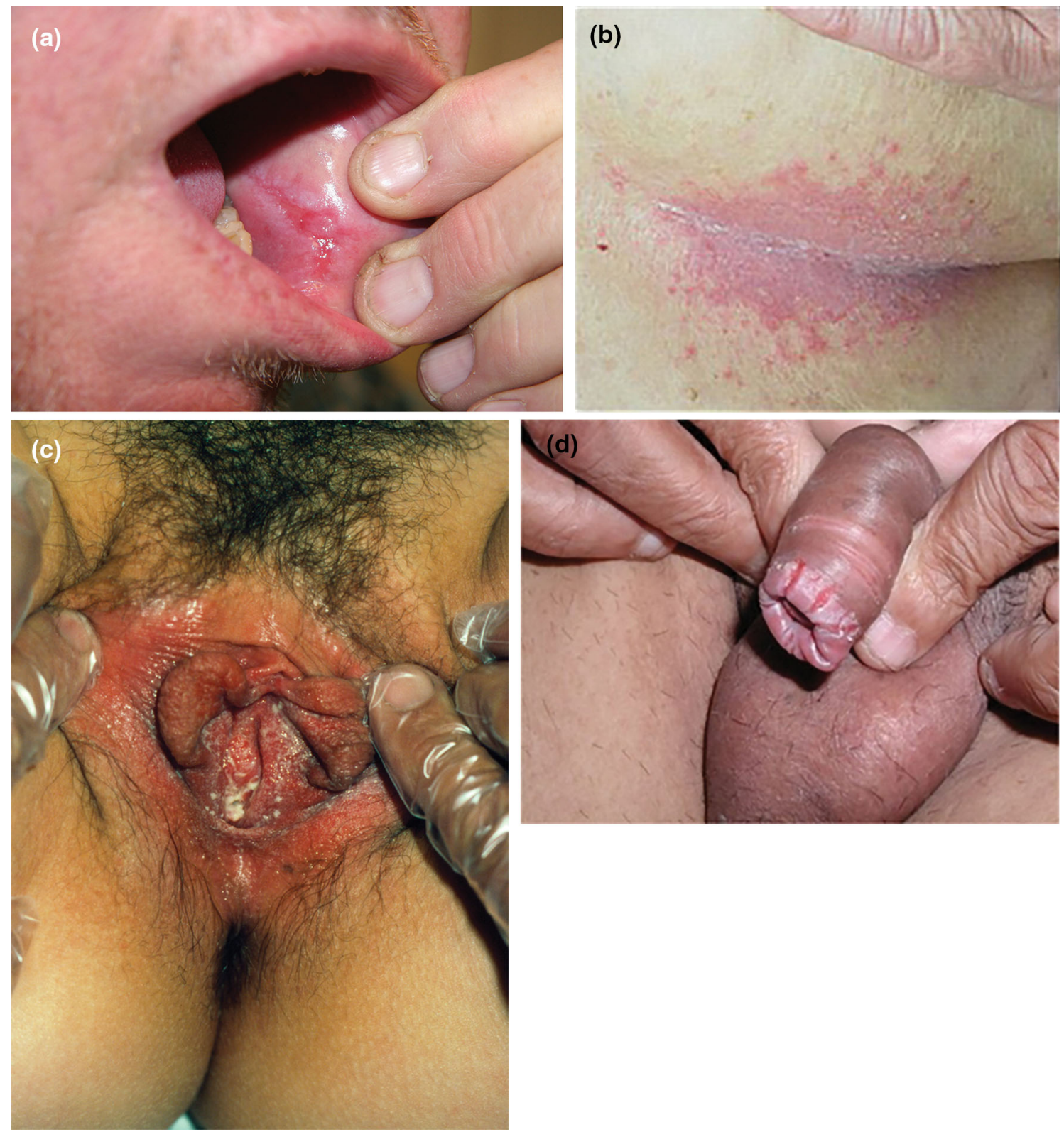

Fig. 1 a Oral candidiasis in a patient with psoriasis. b Intertriginous candidiasis. Reprinted from Janniger et al. [48]. c Vulvovaginal candidiasis. Reprinted from Biophoto Associates/Science Photo Library [49]. d Candidal balanitis with fissuring. Reprinted from Verma and Wollina [50]

albicans, and/or VVC in an abnormal host. Such infections require treatment with topical therapy administered intravaginally daily for approximately 7 days, or multiple oral doses of fluconazole $(150 \mathrm{mg}$ every $72 \mathrm{~h}$ for three doses) [30]. For recurrent VVC, defined as four or more symptomatic episodes within a 1-year period, IDSA guidelines recommend 10-14 days of induction therapy with a topical or oral triazole, followed by fluconazole $150 \mathrm{mg}$ once weekly for 6 months (strength of recommendation: A) [30].

\subsection{Candidal Balanitis}

Candidal balanitis (Fig. 1d) is defined as inflammation of the glans penis in the presence of Candida spp., and accounts for less than $20 \%$ of all balanoposthitis [35]. Candidal balanitis is generally sexually acquired and is more common in patients with diabetes and in uncircumcised men [32]. Infections are almost always opportunistic and often occur in patients with primary inflammatory dermatoses, such as psoriasis [35]. Symptoms include local 
Table 1 IDSA guideline recommendations for oropharyngeal candidiasis [30]

\begin{tabular}{|c|c|c|c|}
\hline Severity of infection & \multicolumn{3}{|c|}{ Treatment (strength of recommendation) } \\
\hline Mild & \multicolumn{3}{|c|}{$\begin{array}{l}\text { Clotrimazole troches }(10 \mathrm{mg} \text {, five times daily), nystatin suspension at a concentration of } 100,000 \mathrm{U} / \mathrm{mL} \text { and a dosage of } \\
4-6 \mathrm{~mL} \text { qid, or } 1-2 \text { nystatin pastilles }(200,000 \mathrm{U} \text { each) administered qid for } 7-14 \text { days, is recommended (B) }\end{array}$} \\
\hline Moderate-to-severe & \multicolumn{3}{|c|}{ Oral fluconazole $100-200 \mathrm{mg}(3 \mathrm{mg} / \mathrm{kg}) \mathrm{qd}$ for $7-14$ days is recommended (A) } \\
\hline $\begin{array}{l}\text { Refractory to } \\
\text { fluconazole }\end{array}$ & \multicolumn{3}{|c|}{$\begin{array}{l}\text { Itraconazole solution } 200 \mathrm{mg} \text { qd, or posaconazole suspension at } 400 \mathrm{mg} \text { bid for } 3 \text { days, then } 400 \mathrm{mg} \text { qd for up to } 28 \\
\text { days, is recommended (A) } \\
\text { Voriconazole } 200 \mathrm{mg} \text { bid, or a } 1 \mathrm{~mL} \text { oral suspension of } \mathrm{AmB}-\mathrm{d}(100 \mathrm{mg} / \mathrm{mL} \text { qid), is recommended when treatment with } \\
\text { other agents has failed (B) } \\
\text { Intravenous echinocandin or AmB-d at a dosage of } 0.3 \mathrm{mg} / \mathrm{kg} \text { qd can be used for treating patients with refractory disease } \\
\text { (B) }\end{array}$} \\
\hline \multicolumn{4}{|c|}{ AmB- $d$ amphotericin B deoxycholate, bid twice daily, IDSA Infectious Diseases Society of America, $q d$ once daily, qid four times daily } \\
\hline \multicolumn{2}{|l|}{ Tradename } & Formulation & Dosing \\
\hline \multicolumn{2}{|l|}{ Canesten $^{\circledR} 1$} & Clotrimazole $10 \%$ cream & Intravaginally for 1 day \\
\hline \multicolumn{2}{|l|}{ Canesten ${ }^{\circledR} 3$} & Clotrimazole $2 \%$ cream & Intravaginally for 3 days \\
\hline \multicolumn{2}{|l|}{ Canesten $^{\circledR} 6$} & Clotrimazole $1 \%$ cream & Intravaginally for 6 days \\
\hline \multicolumn{2}{|c|}{ Canesten $^{\circledR} 1$ combipak cream } & $\begin{array}{l}\text { Clotrimazole } 10 \% \text { cream and clotrimazole } 1 \% \\
\text { external cream }\end{array}$ & $\begin{array}{l}\text { Intravaginally for } 1 \text { day and external cream } \\
\text { once to twice daily for } 7 \text { days }\end{array}$ \\
\hline \multicolumn{2}{|c|}{ Canesten $^{\circledR} 1$ combipak comfortab } & $\begin{array}{l}\text { Clotrimazole } 500 \mathrm{mg} \text { vaginal tablet and } \\
\text { clotrimazole } 1 \% \text { external cream }\end{array}$ & $\begin{array}{l}\text { Intravaginally for } 1 \text { day and external cream } \\
\text { once to twice daily for } 7 \text { days }\end{array}$ \\
\hline \multicolumn{2}{|c|}{ Canesten $^{\circledR} 3$ combipak comfortab } & $\begin{array}{l}\text { Clotrimazole } 200 \mathrm{mg} \text { vaginal tablet and } \\
\text { clotrimazole } 1 \% \text { external cream }\end{array}$ & $\begin{array}{l}\text { Intravaginally for } 3 \text { days and external cream } \\
\text { once to twice daily for } 7 \text { days }\end{array}$ \\
\hline \multicolumn{2}{|l|}{ Gynazole $^{\circledR} 1$} & Butoconazole $2 \%$ cream & Intravaginally for 1 day \\
\hline \multicolumn{2}{|c|}{ Monistat $^{\circledR} 1$} & Tioconazole ointment $6.5 \%$ & Intravaginally for 1 day \\
\hline \multicolumn{2}{|c|}{ Monistat $^{\circledR} 1$ maximum strength } & $\begin{array}{l}\text { Miconazole } 1200 \mathrm{mg} \text { vaginal suppository and } \\
\text { miconazole } 2 \% \text { external cream }\end{array}$ & $\begin{array}{l}\text { Intravaginally for } 1 \text { day and external cream } \\
\text { twice daily for } 7 \text { days }\end{array}$ \\
\hline \multicolumn{2}{|l|}{ Monistat $^{(\circledR)} 3^{\mathrm{a}}$} & $\begin{array}{l}\text { Miconazole } 200 \mathrm{mg} \text { vaginal suppository or } \\
\text { cream }\end{array}$ & Intravaginally for 3 days \\
\hline \multicolumn{2}{|l|}{ Monistat $^{\circledR} 7^{\mathrm{a}}$} & Miconazole $2 \%$ vaginal cream & Intravaginally for 7 days \\
\hline \multicolumn{2}{|l|}{ Terazole $^{\circledR} 3$} & $\begin{array}{l}\text { Terconazole } 80 \mathrm{mg} \text { vaginal suppository or } 0.8 \% \\
\text { cream }\end{array}$ & Intravaginally for 3 days \\
\hline \multicolumn{2}{|l|}{ Terazole $^{\circledR} 7$} & Terconazole $0.4 \%$ cream & Intravaginally for 7 days \\
\hline
\end{tabular}

${ }^{a}$ Available with and without miconazole $2 \%$ external cream for use twice daily for 7 days

burning, soreness, and pruritus, and clinical features include pronounced erythema and papules [32, 35]. Diagnosis is often based on clinical appearance [32], but European consensus guidelines recommend performing a subpreputial culture to confirm the presence of Candida [35].

European guidelines for the management of candidal balanitis recommend treatment with $1 \%$ clotrimazole cream applied twice daily until symptoms resolve or, if symptoms are severe, oral fluconazole $150 \mathrm{mg}$ once daily (strength of recommendation for both: A) [35]. Application of $2 \%$ miconazole cream twice daily until symptoms resolve or, if resistance or allergy to imidazoles is suspected, nystatin cream (100,000 units/g) is also recommended (strength of recommendation for both: B). Topical imidazole with $1 \%$ hydrocortisone can be used if marked inflammation is present (strength of recommendation: C) [35].

\section{Recommendations for Treating Candidiasis in Patients with Psoriasis}

Candida infections in patients with psoriasis often develop in areas that are not readily visible and are often asymptomatic. Dermatologists should be attentive to the presence of mucocutaneous Candida infections when examining a patient with psoriasis. As outlined in Table 3, dermatologists should inquire about oral or genital discomfort to identify potential oropharyngeal or genitourinary 
Table 3 Questions to aid in the diagnosis of candidiasis

\author{
Have you experienced pain or burning in the mouth or on the tongue? \\ Have you experienced denture pain that does not resolve? \\ Have you experienced pain during swallowing? \\ Have you experienced pain or itching in the genital area? \\ Have you experienced pain during urination or intercourse? \\ Have you experienced a vaginal discharge?
}

candidiasis, especially if a full-body examination is not conducted during the patient visit.

Based on our clinical experience, candidiasis in patients with psoriasis, who do not have other underlying immunocompromising conditions, is usually superficial and localized. Additionally, Candida infections do not typically exacerbate psoriasis. Treatment is almost always definitive, and it is uncommon for systemic dissemination to occur. Standard antifungal treatment regimens are generally safe and well tolerated in patients with psoriasis, and treatmentrelated complications are rare. We agree with current guidelines for the treatment of Candida infections, and Tables 1 and 2 can be used to help guide therapy decisions. Physicians should refer to their local or regional guidelines because there may be variations on available treatment options. In our experience, patients with psoriasis are generally more prone to Candida colonization and infections than patients with other chronic dermatoses. Furthermore, the treatment of candidiasis in patients with psoriasis should take into consideration that many individuals with psoriasis are receiving immunosuppressive regimens.

There is evidence to suggest that systemic antifungal therapy can improve psoriasis symptoms in patients with Candida colonization or infection [6, 8]. Such improvement may be a result of a reduction in superantigenic factors produced by Candida that activate $\mathrm{T}$ cells to produce cytokines involved in the pathogenesis of psoriasis [8]. Therefore, adjuvant antifungal therapy may be considered for patients with psoriasis who have high levels of Candida in their saliva or faeces [6]. In addition, all patients with psoriasis should be advised to practice good hygiene to prevent Candida infections. Dentures or removable orthodontics should be cleaned appropriately to prevent the development of biofilms, which are susceptible to $C$. albicans colonization [36].

Based on our clinical experience with currently available psoriasis therapies and analysis of the clinical literature, it is our recommendation that psoriasis treatment should not be altered or interrupted if patients develop candidiasis. Although candidiasis is among the most prevalent type of fungal infection in patients receiving tumor necrosis factor- $\alpha(\mathrm{TNF} \alpha)$ inhibitors, overall rates of infection are low, and infections are generally not severe $[14,37,38]$. A US claims database analysis highlighted that, although candidiasis infections were infrequent in patients with Crohn's disease (176 infections/10,000 person-years in patients with Crohn's disease vs. 94 infections $/ 10,000$ person-years in the general population), infections were more likely in patients receiving anti-TNFa therapy compared with the general population [rate ratio $2.50,95 \%$ confidence interval (CI) 1.73-3.63] and in patients receiving anti-TNF $\alpha$ therapy compared with those receiving no therapy (hazard ratio 2.10, $95 \%$ CI 1.06-4.17) [14]. In an analysis of data from the Spanish BIOBADASER registry of patients with rheumatic disease treated with TNFa inhibitors, $C$. albicans was identified as the cause of $70 \%$ of all fungal infections. Most C. albicans infections were oral $(42.1 \%)$ or genital $(41.7 \%)$ [38]. Among US patients receiving anti-TNF $\alpha$ therapy, Candida infections were more common with infliximab (10.15 cases/100,000 persons) than with etanercept (5.31 cases/ 100,000 persons; $p=0.061$ ) $[39,40]$. During 5 years of postmarketing surveillance in patients with moderate-tosevere psoriasis receiving adalimumab, oral candidiasis was observed at a rate of 0.1 events/100 patient-years [41]. Limited evidence is available regarding the incidence of candidiasis with other systemic agents. In patients with rheumatoid arthritis, oral candidiasis was reported in $10.7 \%$ of individuals receiving low-dose methotrexate (5-20 mg weekly) compared with $4.8 \%$ of individuals receiving other therapies [12].

The IL-17 pathway has been demonstrated to regulate mucocutaneous defense against $C$. albicans through upregulation of IL-6, neutrophil-recruiting chemokines (CXCL1 and CXCL5), and antimicrobial peptides (defensins) [42]. Thus, it is not surprising that candidiasis has been reported in patients receiving treatment with $\mathrm{IL}-17$ inhibitors. The IL-17A inhibitors secukinumab and ixekizumab were recently approved for the treatment of moderate-to-severe plaque psoriasis [16, 43]. In the phase III FIXTURE study, rates of Candida infections over 52 weeks were $4.7 \%$ with secukinumab $300 \mathrm{mg}, 2.3 \%$ with secukinumab $150 \mathrm{mg}$, and $1.2 \%$ with etanercept (placebo not reported) [16]. In pooled results from the ixekizumab phase III UNCOVER-2 and UNCOVER-3 studies, the rates of Candida infections over 12 weeks were $1.6 \%$ with ixekizumab $80 \mathrm{mg}$ every 2 weeks, $0.5 \%$ with ixekizumab $80 \mathrm{mg}$ every 4 weeks, $0.7 \%$ with etanercept, and $0.6 \%$ with placebo [43]. At week 12 in the smaller secukinumab phase III FEATURE and JUNCTURE trials, the rates of 
Candida infections were 3.4 and $0 \%$ with secukinumab $300 \mathrm{mg}, 1.7$ and $1.6 \%$ with secukinumab $150 \mathrm{mg}$, and 0 and $1.6 \%$ with placebo, respectively $[10,18]$. Candidiasis was also reported with brodalumab, which targets IL17RA, a component of the IL-17A receptor. In the AMAGINE-2 and AMAGINE-3 trials, Candida infections were reported in 4.5-5.0\% of patients receiving any dose of brodalumab, and in $1.3-3.3 \%$ of patients receiving ustekinumab [44]. These infections were generally mild, non-serious, and localized; they did not require interruption of psoriasis treatment and typically resolved with standard antifungal therapy. Thus, the risk of developing candidiasis does not appear to outweigh the benefits of therapy with biologic agents, which provide significant psoriasis disease clearance and symptom reduction. Candida infections that do occur during psoriasis treatment are generally manageable and do not warrant a change in therapy.

It is interesting to note that patients with psoriasis are more likely to develop candidiasis than normal controls since IL-17 is implicated in the pathogenesis of psoriasis [45]. This susceptibility is possibly due to overall immune dysregulation in patients with psoriasis. To this point, patients with psoriasis have a reduction in humoral immune responses and significantly lower levels of serum $\operatorname{IgM}, \operatorname{IgA}$, and IgG against $C$. albicans compared with controls [46]. Furthermore, differences is serum levels of IL-17 were not detected between patients with psoriasis and controls, but IL-17 messenger RNA (mRNA) levels were significantly elevated in psoriatic skin [47]. Thus, it is not surprising that inhibition of IL-17 results in an increased rate of candidiasis as elevations in IL-17 appear to be localized to lesional skin in patients with psoriasis.

\section{Conclusions}

Psoriasis is associated with an increased risk for candidiasis, and therapies used to treat psoriasis may increase this risk [10]. With the availability of biologic therapies that target cytokines involved in host defense mechanisms (e.g. IL-17A), treatment-related Candida infections are to be expected in a small percentage of patients who receive these agents for the management of moderate-to-severe psoriasis. Thus, it is important for dermatologists to be aware of the symptoms of candidiasis and to know how to manage these symptoms according to current guideline recommendations. With effective management for candidiasis, psoriasis patients do not need to experience disruption in their systemic psoriasis therapies.

Acknowledgments Technical assistance with editing and styling of the manuscript for submission was provided by Oxford PharmaGenesis Inc., and was funded by Novartis Pharmaceuticals Corporation.

\section{Compliance with Ethical Standards}

The authors were fully responsible for all content and editorial decisions and received no financial support or other form of compensation related to the development of this article. The opinions expressed in the article are those of the authors, and Novartis Pharmaceuticals had no influence on the contents.

Dr. Armstrong has served as an investigator and/or has consulted for AbbVie, Amgen, Celgene, Janssen, Merck, Eli Lilly, Celgene, Novartis, and Pfizer. Dr. Bukhalo has served as an investigator and/or has consulted for Novartis, LeoPharma, Boehringer Ingelheim, Eli Lilly, Merck, DUSA Pharmaceuticals, Centocor, Allergan, Celgene, Galderma, and Coherus, and as a speaker for Novartis. Dr. Blauvelt has served as a scientific consultant and clinical study investigator for AbbVie, Amgen, Boehringer Ingelheim, Celgene, Dermira, Genentech, Janssen, Eli Lilly, Merck, Novartis, Pfizer, and Sandoz.

Open Access This article is distributed under the terms of the Creative Commons Attribution-NonCommercial 4.0 International License (http://creativecommons.org/licenses/by-nc/4.0/), which permits any noncommercial use, distribution, and reproduction in any medium, provided you give appropriate credit to the original author(s) and the source, provide a link to the Creative Commons license, and indicate if changes were made.

\section{References}

1. Nestle FO, Kaplan DH, Barker J. Psoriasis. N Engl J Med. 2009;361:496-509.

2. De Luca A, Zelante T, D'Angelo C, Zagarella S, Fallarino F, Spreca A, et al. IL-22 defines a novel immune pathway of antifungal resistance. Mucosal Immunol. 2010;3:361-73.

3. Kisand K, Bøe Wolff AS, Podkrajšek KT, Tserel L, Link M, Kisand $\mathrm{KV}$, et al. Chronic mucocutaneous candidiasis in APECED or thymoma patients correlates with autoimmunity to Th17-associated cytokines. J Exp Med. 2010;207:299-308.

4. Huppler AR, Conti HR, Hernández-Santos N, Darville T, Biswas PS, Gaffen SL. Role of neutrophils in IL-17-dependent immunity to mucosal candidiasis. J Immunol. 2014;192:1745-52.

5. Kagami S, Rizzo HL, Kurtz SE, Miller LS, Blauvelt A. IL-23 and IL-17A, but not IL-12 and IL-22, are required for optimal skin host defense against Candida albicans. J Immunol. 2010;185:5453-62.

6. Waldman A, Gilhar A, Duek L, Berdicevsky I. Incidence of Candida in psoriasis: a study on the fungal flora of psoriatic patients. Mycoses. 2001;44:77-81.

7. Sarvtin MT, Shokohi T, Hajheydari Z, Yazdani J, Hedayati MT. Evaluation of candidal colonization and specific humoral responses against Candida albicans in patients with psoriasis. Int J Dermatol. 2014;53:e555-60.

8. Fry L, Baker BS. Triggering psoriasis: the role of infections and medications. Clin Dermatol. 2007;25:606-15.

9. Leibovici V, Alkalay R, Hershko K, Ingber A, Westerman M, Leviatan-Strauss N, et al. Prevalence of Candida on the tongue and intertriginous areas of psoriatic and atopic dermatitis patients. Mycoses. 2008;51:63-6.

10. Blauvelt A, Lebwohl MG, Bissonnette R. IL-23/IL-17A dysfunction phenotypes inform possible clinical effects from anti-IL17A therapies. J Invest Dermatol. 2015;135:1946-53.

11. Darwazeh AM, Al-Aboosi MM, Bedair AA. Prevalence of oral mucosal lesions in psoriatic patients: a controlled study. J Clin Exp Dent. 2012;4:e286-91. 
12. Pedrazas $\mathrm{CH}$, Azevedo MN, Torres SR. Oral events related to low-dose methotrexate in rheumatoid arthritis patients. Braz Oral Res. 2010;24:368-73.

13. Greenblatt MB, Aliprantis A, Hu B, Glimcher LH. Calcineurin regulates innate antifungal immunity in neutrophils. J Exp Med. 2010;207:923-31.

14. Marehbian J, Arrighi HM, Hass S, Tian H, Sandborn WJ. Adverse events associated with common therapy regimens for moderate-to-severe Crohn's disease. Am J Gastroenterol. 2009;104:2524-33.

15. Blauvelt A, Prinz JC, Gottlieb AB, Kingo K, Sofen H, RuerMulard M, et al. Secukinumab administration by pre-filled syringe: efficacy, safety, and usability results from a randomized controlled trial in psoriasis (FEATURE). $\mathrm{Br} \mathrm{J}$ Dermatol. 2015;172:484-93.

16. Langley RG, Elewski BE, Lebwohl M, Reich K, Griffiths CE, Papp K, et al. Secukinumab in plaque psoriasis: results of two phase 3 trials. N Engl J Med. 2014;371:326-38.

17. Corazza M, Zauli S, Ricci M, Borghi A, Rossi R, Virgili A. Does anti-tumour necrosis factor-alpha increase oral candida colonization? A case-control study in psoriatic patients. Acta Derm Venereol. 2013;93:352-3.

18. Paul C, Lacour JP, Tedremets L, Kreutzer K, Jazayeri S, Adams $\mathrm{S}$, et al. Efficacy, safety and usability of secukinumab administration by autoinjector/pen in psoriasis: a randomized, controlled trial (JUNCTURE). J Eur Acad Dermatol Venereol. 2015;29:1082-90.

19. McManus BA, Coleman DC. Molecular epidemiology, phylogeny and evolution of Candida albicans. Infect Genet Evol. 2014;21:166-78.

20. Singh G, Urhekar RA. Candidal infection: epidemiology, pathogenesis and recent advances for diagnosis. Bull Pharm Med Sci. 2013;1:1-8.

21. Nenoff P, Krüger C, Schaller J, Ginter-Hanselmayer G, SchulteBeerbühl R, Tietz HJ. Mycology—an update part 2: dermatomycoses: clinical picture and diagnostics. J Dtsch Dermatol Ges. 2014;12:749-77.

22. Aaron DM. The Merck Manual Professional Edition. Candidiasis (Mucocutaneous). 2013. Available at: http://www.merckmanuals. $\mathrm{com} /$ professional/dermatologic-disorders/fungal-skin-infections/ candidiasis-mucocutaneous. Accessed 11 Aug 2015.

23. Takemoto A, Cho O, Morohoshi Y, Sugita T, Muto M. Molecular characterization of the skin fungal microbiome in patients with psoriasis. J Dermatol. 2015;42:166-70.

24. Picciani BL, Michalski-Santos B, Carneiro S, Sampaio AL, Avelleira JC, Azulay DR, et al. Oral candidiasis in patients with psoriasis: correlation of oral examination and cytopathological evaluation with psoriasis disease severity and treatment. J Am Acad Dermatol. 2013;68:986-91.

25. Fischer G. Chronic vulvitis in pre-pubertal girls. Australas J Dermatol. 2010;51:118-23.

26. Zaias N, Escovar SX, Zaiac MN. Finger and toenail onycholysis. J Eur Acad Dermatol Venereol. 2015;29:848-53.

27. Zisova L, Valtchev V, Sotiriou E, Gospodinov D, Mateev G. Onychomycosis in patients with psoriasis: a multicentre study. Mycoses. 2012;55:143-7.

28. Miller DJ. Diagnosis and management of Candida and other fungal infections of the head and neck. Curr Infect Dis Rep. 2002;4:194-200.

29. Cuenca-Estrella M, Verweij PE, Arendrup MC, ArikanAkdagli S, Bille J, Donnelly JP, et al. ESCMID* guideline for the diagnosis and management of Candida diseases 2012: diagnostic procedures. Clin Microbiol Infect. 2012;18(Suppl 7):9-18

30. Pappas PG, Kauffman CA, Andes D, Benjamin DK Jr, Calandra $\mathrm{TF}$, Edwards JE Jr, et al. Clinical practice guidelines for the management of candidiasis: 2009 update by the Infectious Diseases Society of America. Clin Infect Dis. 2009;48:503-35.

31. Rex JH, Walsh TJ, Sobel JD, Filler SG, Pappas PG, Dismukes WE, et al. Practice guidelines for the treatment of candidiasis. Infectious Diseases Society of America. Clin Infect Dis. 2000;30:662-78.

32. Achkar JM, Fries BC. Candida infections of the genitourinary tract. Clin Microbiol Rev. 2010;23:253-73.

33. Welsh B, Howard A, Cook K. Vulval itch. Aust Fam Physician. 2004:33:505-10.

34. Del-Cura González I, Garciá-de-Blas González F, Cuesta TS, Martín Fernández J, Del-Alamo Rodríguez JM, Escriva Ferrairo RA, et al. Patient preferences and treatment safety for uncomplicated vulvovaginal candidiasis in primary health care. BMC Public Health. 2011;11:63.

35. Edwards S, Bunker C, Ziller F, van der Meijden WI. 2013 European guideline for the management of balanoposthitis. Int $\mathrm{J}$ STD AIDS. 2014;25:615-26.

36. Hoshi N, Mori H, Taguchi H, Taniguchi M, Aoki H, Sawada T, et al. Management of oral candidiasis in denture wearers. J Prosthodont Res. 2011;55:48-52.

37. Tsiodras S, Samonis G, Boumpas DT, Kontoyiannis DP. Fungal infections complicating tumor necrosis factor $\alpha$ blockade therapy. Mayo Clin Proc. 2008;83:181-94.

38. Pérez-Sola MJ, Torre-Cisneros J, Pérez-Zafrilla B, Carmona L, Descalzo MA, Gómez-Reino JJ, et al. Infections in patients treated with tumor necrosis factor antagonists: incidence, etiology and mortality in the BIOBADASER registry. Med Clin (Barc). 2011;137:533-40.

39. Wallis RS, Broder M, Wong J, Beenhouwer D. Granulomatous infections due to tumor necrosis factor blockade: correction. Clin Infect Dis. 2004;39:1254-5.

40. Wallis RS, Broder MS, Wong JY, Hanson ME, Beenhouwer DO. Granulomatous infectious diseases associated with tumor necrosis factor antagonists. Clin Infect Dis. 2004;38:1261-5.

41. Menter A, Thaci D, Papp KA, Wu JJ, Bereswill M, Teixeira HD, et al. Five-year analysis from the ESPRIT 10-year postmarketing surveillance registry of adalimumab treatment for moderate to severe psoriasis. J Am Acad Dermatol. 2015;73(410-9):e6.

42. Conti HR, Gaffen SL. IL-17-mediated immunity to the opportunistic fungal pathogen candida albicans. J Immunol. 2015;195:780-8.

43. Griffiths CE, Reich K, Lebwohl M, van de Kerkhof P, Paul C, Menter A, et al. Comparison of ixekizumab with etanercept or placebo in moderate-to-severe psoriasis (UNCOVER-2 and UNCOVER-3): results from two phase 3 randomised trials. Lancet. 2015;386:541-51.

44. Lebwohl M, Strober B, Menter A, Gordon K, Weglowska J, Puig L, et al. Phase 3 studies comparing brodalumab with ustekinumab in psoriasis. N Engl J Med. 2015;373:1318-28.

45. Durham LE, Kirkham BW, Taams LS. Contribution of the IL-17 pathway to psoriasis and psoriatic arthritis. Curr Rheumatol Rep. 2015; 17:55.

46. Taheri Sarvtin M, Shokohi T, Hajheydari Z, Yazdani J, Hedayati MT. Evaluation of candidal colonization and specific humoral responses against Candida albicans in patients with psoriasis. Int J Dermatol. 2014;53:e555-60.

47. Yilmaz SB, Cicek N, Coskun M, Yegin O, Alpsoy E. Serum and tissue levels of IL-17 in different clinical subtypes of psoriasis. Arch Dermatol Res. 2012;304:465-9.

48. Janniger CK, Schwartz RA, Szepietowski JC, Reich A. Intertrigo and common secondary skin infections. Am Fam Physician. $2005 ; 72: 833-8$.

49. Vaginal thrush. Biophoto Associates/Science Photo Library. Available at: http://www.sciencephoto.com/. Accessed 2 Sept 2015.

50. Verma SB, Wollina U. Looking through the cracks of diabetic candidal balanoposthitis! Int J Gen Med. 2011;4:511-3. 